\title{
Laparoscopic and robotic ventral hernia repair in obese and morbidly obese patients: initial experience and review of the literature
}

\begin{abstract}
Introduction: Laparoscopic repair of large parietal wall defects is a well-accepted and safe option for class II and class III obesity patients. Apart from cardiorespiratory and anesthesiological parameters, main concerns with such patients include the relatively higher risks of wound infection and recurrencies as well as postoperative hemorrhage and port-site hernias. However, advantages over classic - open repairs are well demarcated in the literature. Robotic surgery is a newcomer in the field of hernia surgery with unknown superiority towards older, established approaches.
\end{abstract}

Material: Nine hernia repairs were performed in eight patients with BMIs $>35$, aged 31-74 years. Their hernias were epigastric $(n=2)$, umbilical $(n=3)$ and incisional $(\mathrm{n}=4)$. All patients underwent full preoperative workup, including history, physical examination, evaluation from cardiologist, anesthesiologist, as well as pneumologist and gave consent for the procedures as well as for this paper. Large incisional hernias were treated with self-expanding or self-adhering mesh. A robotic approach was used in five cases. One patient, who underwent a sleeve gastrectomy, had his umbilical hernia repaired during the same procedure.

Results: All eight patients followed an uncomplicated course. Patients were discharged as soon as bowel function returned (postoperative days 2-4). Seromas developed in four patients and were treated by aspiration of the collection. In our largest patient $(\mathrm{BMI}=47)$ an infection of the camera port site was noted on postoperative day 7 , and was drained succesfully on an outpatient basis.

Conclusion: Initial access and induction of pneumoperitoneum has been the most challening phase of all hernia repairs in obese patients. Robotics seems to facilitate extensive adhesiolysis during incisional hernia repairs. Self-expanding meshes aid fast and correct placement of the mesh in large defects, decreasing technical challenges.
Volume 8 Issue 5 - 2018

\author{
Hirides S, Verveniotis N, Galanopoulou R, \\ Metaxas P, Polyzou A, Hirides P \\ Athens Medical Center, Greece
}

Correspondence: Savvas Hirides, Athens Medical Center, Greece, Email: savashiridis@gmail.com

Received: August 10,2018| Published: October 01, 2018

\section{Introduction}

According to latest literature laparoscopic repair of large parietal wall defects is a well-accepted and safe option for class II and class III obesity patients. Apart from cardiorespiratory and anesthesiological parameters, main concerns with such patients include the relatively higher risks of wound infections and recurrencies as well as postoperative hemorrhage and port-site hernias. However, advantages over classic - open repairs are well demarcated in the literature. Recent introduction of robotics in bariatric as well as hernia surgery brings up new hopes for expansion of the indications to patients with very large incisional hernias and loss of domain. Our aim in this paper is to present a single surgeon's technique with laparoscopic and robotic parietal wall defect repairs in morbidly obese patients and review latest literature for main concerns of a novice team.

\section{Material}

In 2007 the authors joined a fellowship program at an IFSOaccredited private clinic in Athens Medical Center, Athens, Greece with large experience in gastric banding, sleeve gastrectomy, robotic bariatric redo cases and hernia repairs in obese patients. In 2009 they became part of this clinical team and gained experience from 114 laparoscopic and robotic bariatric cases and 1679 hernia repairs in the period 2009-2017. Based on this experience, the authors initiated their own bariatric ${ }^{1}$ and hernia programs in the same institution.
During a single surgeon's cumulative experience of 111 laparoscopic hernia repairs (87 inguinal, 16 ventral-incisional, 9 umbilical hernia repairs), eight of these patients presented with a BMI $>35$. Four of them with a BMI $>40$ (Class III obesity). Nine hernia repairs were performed in eight patients with BMIs $>35$, aged 31-74 years (Table 1). Their hernias were epigastric $(n=2)$, umbilical $(n=3)$ and incisional $(\mathrm{n}=4)$. Apart from standard full preoperative workup, including history, physical examination, evaluation from cardiologist and anesthesiologist, laboratory and imaging examinations, our morbid obese patients also had to consult with our pneumologist and dietician 1 month prior to the operation. A large $20 \times 25 \mathrm{~cm}$ selfexpanding mesh was used in three cases. One patient had both an incisional (rare flank hernia after right nephrectomy) and an umbilical hernia repaired during the same procedure. One patient with epigastric hernia underwent a concomitant liver biopsy. One of the umbilical hernia cases underwent repair during a synchronous sleeve gastrectomy procedure.

All patients signed an informed consent prior to the procedures, including their approval for publishing their results in this paper. Perioperative thromboprophylaxis is performed as a routine by our team using LMW heparin according to body weight, and intermittent pneumatic compression devices are routinely used intraoperatively. 
Table I Nine hernia repairs were performed in eight patients with BMls $>35$, aged $3 \mathrm{I}-74$ years

\begin{tabular}{|c|c|c|c|c|c|c|c|c|c|c|}
\hline Patient & $\begin{array}{l}\text { Age } \\
\text { at } \\
\text { OP }\end{array}$ & BMI & Type of hernia & Approach & $\begin{array}{l}\text { Synchronous } \\
\text { Procedures }\end{array}$ & Material & Complications & $\begin{array}{l}\text { Follow } \\
\text { up }\end{array}$ & Satisfaction & Seroma \\
\hline$\# 1$ & 53 & 47 & Epigastric & Laparoscopic & Adhesiolysis & Self-expand & g mesh & & $\begin{array}{l}\text { Relieved } \\
\text { especially } \\
\text { during coughing. } \\
\text { Satisfied. } \\
\text { Gained } \\
\text { confidence } \\
\text { and lost I } 5 \mathrm{~kg} \\
\text { weight. }\end{array}$ & $\begin{array}{l}\text { At one week } 130 \mathrm{~mL} \text {, } \\
\text { one month } 800 \mathrm{~mL} \text {, } \\
45 \text { days }(400 \mathrm{ml}) \text {, two } \\
\text { months }(80 \mathrm{~mL})\end{array}$ \\
\hline$\# 2$ & 72 & 36,2 & Epigastric & Robotic & Liver Biopsy & Dual mesh & & 2 years & Totally satisfied. & No \\
\hline$\# 3$ & 42 & 36,6 & $\begin{array}{l}\text { Incisional } \\
\text { - multiple } \\
\text { defects }(17 \mathrm{~cm}) \\
\text { after } \\
\text { splenectomy } \\
\text { from a car } \\
\text { accident }\end{array}$ & Robotic & & Self-expand & g mesh & & & $\begin{array}{l}\text { I aspiration for } \\
\text { small seroma after } \\
\text { I week }\end{array}$ \\
\hline$\# 4$ & 51 & 37,03 & $\begin{array}{l}\text { Incisional }(14 \mathrm{~cm}) \\
\text { after open } \\
\text { pancreatectomy/ } \\
\text { Midline }\end{array}$ & Robotic & Adhesiolysis & Self-expand & g mesh & & $\begin{array}{l}\text { Readmitted } \\
4 \text { months } \\
\text { after the } \\
\text { procedure due } \\
\text { to obstructive } \\
\text { ileus related } \\
\text { to his previous } \\
\text { pancreatectomy }\end{array}$ & No \\
\hline$\# 5$ & 43 & 46,32 & Umbilical & $\begin{array}{l}\text { Open repair } \\
\text { during } \\
\text { laparoscopic } \\
\text { sleeve }\end{array}$ & $\begin{array}{l}\text { Sleeve } \\
\text { Gastrectomy }\end{array}$ & \multicolumn{3}{|c|}{$\begin{array}{l}\text { Redon drains for both the gastrectomy as } \\
\text { well as the umbilical. }\end{array}$} & $\begin{array}{l}\text { Relieved from } \\
\text { obstructive } \\
\text { sleep apnea } \\
\text { after bariatric } \\
\text { procedure. Very } \\
\text { satisfied with } \\
\text { umbilical repair }\end{array}$ & No \\
\hline$\# 6$ & 31 & 36,36 & Umbilical & Laparoscopic & & Dual mesh & & & $\begin{array}{l}\text { Uneventful.Very } \\
\text { satisfied. }\end{array}$ & No \\
\hline$\# 7$ & 74 & 40,44 & $\begin{array}{l}\text { Incisional (after } \\
\text { left colectomy } \\
\text { for cancer) }\end{array}$ & Robotic & & Dual mesh & & & & $\begin{array}{l}\text { Twice aspirated for } \\
\text { seroma. }\end{array}$ \\
\hline$\# 8$ & 69 & 41,04 & $\begin{array}{l}\text { Incisional } \\
\text { Flank (after } \\
\text { nephrectomy) } \\
\text { and Umbilical } \\
\text { hernias }\end{array}$ & Robotic & & Self-adhesiv & mesh & & $\begin{array}{l}\text { Uneventful.Vey } \\
\text { satisfied. }\end{array}$ & $\begin{array}{l}\text { Once for small } \\
\text { seroma I week after } \\
\text { the procedure. }\end{array}$ \\
\hline
\end{tabular}

\section{Surgical technique}

A left lateral approach is our usual technique both for a laparoscopic or a robotic repair. For the robotic procedure, the robot has to be positioned on the opposite side, ie on patient's right in order to have correct ergonomy in the OR. Initial incision of $1 \mathrm{~cm}$ is usually extended by a few millimeters, especially in obese patients, because an open (Hasson) access to the abdomen is rather cumbersome. An opti-view trocar has been used in the past by the authors, but today it is avoided, especially in cases where abundant adhesions and altered anatomy is anticipated. After induction of the pneumoperitoneum, two $5 \mathrm{~mm}$ trocars are inserted proximally and caudally to the camera port, along the midclavicular line (Figure 1). Adhesiolysis usually begins with greater omentum stuck on the anterior abdominal wall and then continues with the small bowel loops, especially if they are part of hernial sac content. Care is mandatory here, in order to minimize use of cautery, especially monopolar, to avoid bowel injury. Robotic stereoscopic 3D vision has been found by the authors to facilitate this challenging phase of the procedure. If bowel is injured during adhesiolysis, the authors prefer to repair the damage at the same time,

rather than leaving it untreated for later. A serious perforation should raise the decision for conversion to laparotomy as well as avoiding the use of mesh. Sharp dissection is usually used with cutting down the adhesions by means of monopolar scissors. For blunt dissection the authors prefer to use a sponge held at the tip of a laparoscopic or robotic grasper (Figure 2). After completion of adhesiolysis and reduction of hernia content, a mesh is inserted and expanded with the help of assisting trocars. Self-expanding meshes (Figure 3) are quite practical in case of very large or multiple defects, because technical difficulty has been found to be proportional to the size of the defect and the necessary mesh. Fixation of the mesh takes place with absorbable or non-absorbable material. We usually avoid the use of drains. An exception was made for one of our cases with synchronous sleeve gastrectomy, where we used both an intraabdominal JacksonPratt suction drain, as well as a subcutaneous Redivac suction drain in the area of a very large umbilical hernia repair with excellent results. A patient with flank hernia was treated by extraperitoneal placement of a self-adherent mesh after extended dissection of the right lateral peritoneum. 


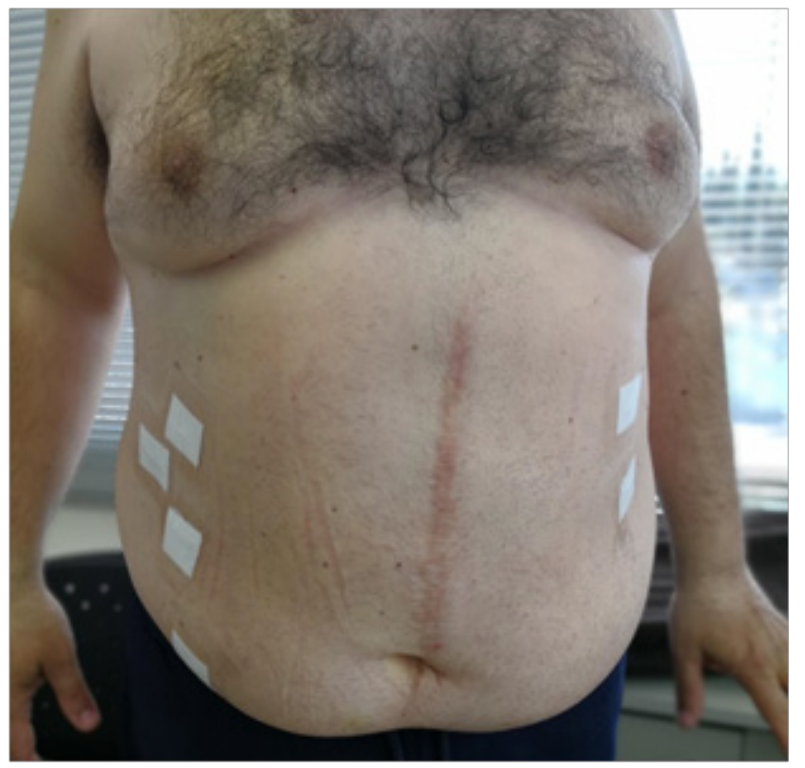

Figure I Positioning of trocars for laparoscopic ventral hernia repair in a patient with $\mathrm{BMI}=47$.

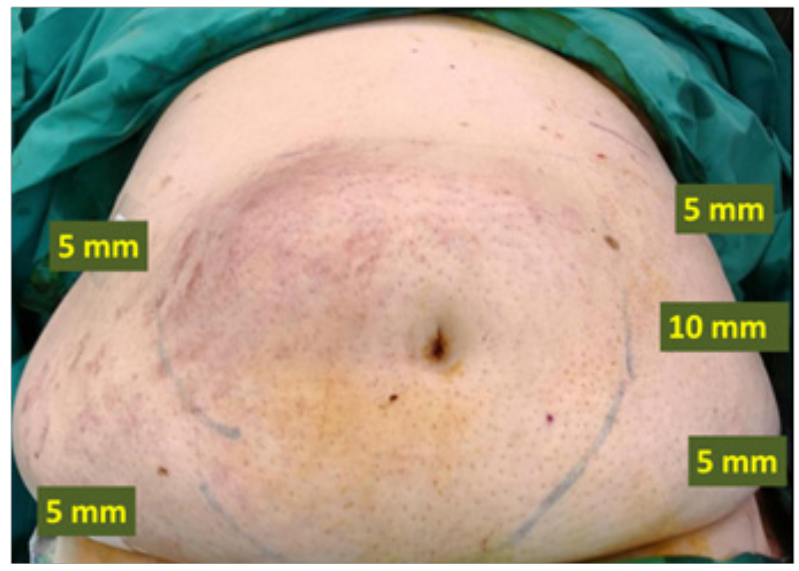

Figure 2 Adhesiolysis and reduction of hernia content prior to repair in a patient with history of open distal pancreatectomy.
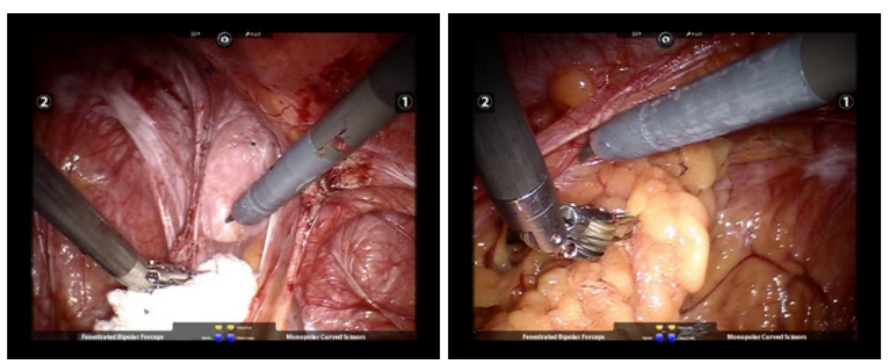

Figure 3 Use of self- expanding mesh in the same patient.

\section{Results}

All eight patients followed an uncomplicated course. Patients were discharged as soon as bowel function was restored (postoperative days 2-4). Seromas developed in four patients and were treated by aspiration of the collections in one or many outpatient visits. In our patient with BMI 47, an infection of the camera port site was noted on postoperative day 7 , and was drained succesfully on an outpatient basis. All ventral hernia patients were instructed to use a truss in the upright position, for one month postoperatively (Figure 4). All patients declared satisfied with their hernia repair; mean satisfaction rate of 9,375 out of 10 (Figure 5).
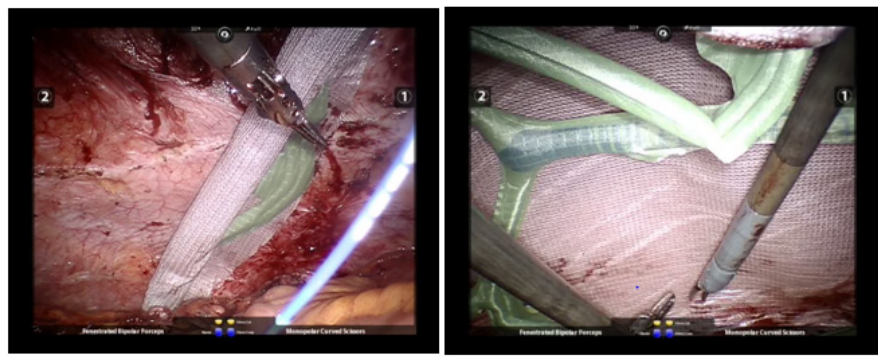

Figure 4 Use of a truss for 4 weeks after the procedure. This patient had a large incisional hernia after previous splenectomy, managed with the above described technique.

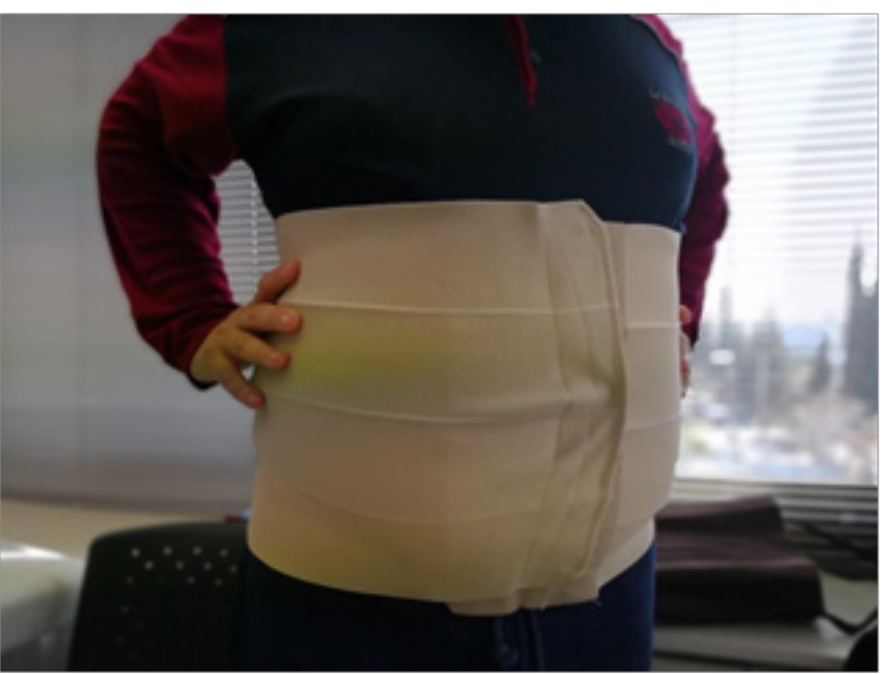

Figure 5 First week postoperative result on the same patient.

\section{Discussion}

Laparoscopic repair of large parietal wall defects is a wellaccepted and safe option for class II and class III obesity patients. ${ }^{2}$ There are many parameters adherent to hernias (size, location, primary versus recurrent, symptomatic versus asymptomatic, reduced versus nonreduced) that may affect the decision to perform a ventral hernia repair during a bariatric procedure. In a 2017 large cohort study there was increased 30 day morbidity, ${ }^{3}$ although specific hernia characteristics were not assesed. Another study showed increased rate of surgical site infections but not of overall morbidity. ${ }^{4}$ Our sleeve gastrectomy case with concomitant umbilical hernia repair followed an excellent postoperative course. Suturing of the hernia instead of a mesh, as well as subcutaneous drainage of potential seroma may have contributed to this good outcome. Self-expading meshes can be of great help in very large or multiple defects. IPOM technique in such cases require numerous tackers for proper fixation of the mesh. Absorbable tackers have been found to detach easily, even during the time of fixation. Novel permanent fixation systems seem to be more efficient than absorbable ones, but sometimes they can be "too strong" so as to pierce through the hernia outside the skin, so caution is advised. In our experience, one of our assistants injured his fingertips 
during such a fixation. We don't routinely use stitches or glues for ventral hernia repairs. ${ }^{5-7}$

Robotic approaches have been proven to be safe and feasible. Potential advantages have been reported occasionally for obese patients, such as easier manipulation with heavy abdominal wall lifting, less need for high pneumoperitoneum pressures and facilitation of liver retraction. A recent comparison of 20,896 laparoscopic and 619 robotic repairs, reports significantly shorter length of hospital stay and lower rate of complications for the robotic group. ${ }^{8}$ However, increased costs cannot justify the use of robotics solely for ventral hernia surgery and use is advised for centers with busy robotic schedules from other specialties. In our institution the robot has been used from four urologic teams, two general surgery teams and one gynecologic team for the past 12 years. Hernia repair was easily incorporated in such a busy robotic program, although the overall costs of the procedure remained high in comparison to conventional laparoscopic technique. Fundamental questions for the correct approach cannot be satisfactorily answered today due to lack of comprehensive clinical data collection. ${ }^{7}$ In our small experience, standardization of such procedures can be extremely difficult, even from a single-surgeon experience, because of the multifactorial character of these patients and their pathology. ${ }^{8-12}$

\section{Conclusion}

Initial access and induction of pneumoperitoneum has been the most challenging phase of all hernia repairs in obese patients. Robotic surgery appears to facilitate extensive adhesiolysis during incisional hernia repairs and probably offers a protective role for salvation of small bowel loops. Self-expanding meshes aid fast and correct placement of the mesh in large defects, decreasing technical challenges but caution is suggested with the new generation of "stronger" tacking devices.

\section{Acknowledgments}

None.

\section{Conflicts of interest}

The author declares there are no conflicts of interest.

\section{References}

1. SC Hirides, PC Hirides. Concerns during Initiation of Sleeve Gastrectomy in a Laparoscopic Bariatric Program: A Single Surgeon's Initial Experience and Review of Latest Literature. Adv Obes Weight Manag Control. 2018;8(1):17-23.
2. Marx L, Raharimanantsoa M, Mandala S, et al. Laparoscopic treatment of incisional and primary ventral hernia in morbidly obese patients with a BMI over 35. Surg Endosc. 2014;28(12):3310-3314.

3. Khorgami Z, Haskins IN, Aminian A, et al. Concurrent ventral hernia repair in patients undergoing laparoscopic bariatric surgery: a case-matched study using the National Surgical Quality Improvement Program Database. Surgery for Obesity and Related Diseases. 2017;13(6):997-1002.

4. Spaniolas K, Kasten KR, Mozer AB, et al. Synchronous Ventral Hernia Repair in Patients Undergoing Bariatric Surgery. Obes Surg. 2015;25(10):1864-1868.

5. Rosen MJ, Aydogdu K, Grafmiller K, et al. A Multidisciplinary Approach to Medical Weight Loss Prior to Complex Abdominal Wall Reconstruction: Is it Feasible? J Gastrointest Surg. 2015;19(8):1399-1406.

6. Liang MK, Goodenough CJ, Martindale RG, et al. External Validation of the Ventral Hernia Risk Score for Prediction of Surgical Site Infections. Surg Infect. 2015;16(1):36-40.

7. Varban O,Telem DA. Management of ventral hernia during bariatric surgery: a plea for quality data for quality improvement. Surg Obes Relat Dis. 2017;13(6):1002-1003.

8. Altieri MS, Yang J, Xu J, et al. Outcomes after Robotic Ventral Hernia Repair: A Study of 21,565 Patients in the State of New York. Am Surg. 2018;84(6):902-908.

9. Belyansky I, Reza Zahiri H,Sanford Z, et al. Early operative outcomes of endoscopic (eTEP access) robotic-assisted retromuscular abdominal wall hernia repair. Hernia. 2018

10. Ahmed MA,Tawfic QA, Schlachta CM, et al. Pain and Surgical Outcomes Reporting After Laparoscopic Ventral Hernia Repair in Relation to Mesh Fixation Technique: A Systematic Review and Meta-Analysis of Randomized Clinical Trials. J Laparoendosc Adv Surg Tech A. USA; 2018.

11. Beffa LR, Margiotta AL, Carbonell AM, et al. Flank and Lumbar Hernia Repair. Surg Clin North Am. 2018;98(3):593-605.

12. Appleby PW, Martin TA, Hope WW, et al. Umbilical Hernia Repair: Overview of Approaches and Review of Literature. Surg Clin North Am. 2018;98(3):561-576. 